Article

\title{
Housing First in Denmark: An Analysis of the Coverage Rate among Homeless People and Types of Shelter Users
}

\author{
Lars Benjaminsen \\ The Danish Center for Social Science Research, 1052 Copenhagen, Denmark; E-Mail: lab@vive.dk
}

Submitted: 6 April 2018 | Accepted: 4 July 2018 | Published: 28 September 2018

\begin{abstract}
A paradigm shift has taken place regarding the understanding of homelessness interventions in recent years as Housing First-early access to permanent housing in combination with intensive social support-has been shown to improve the chances of rehousing for homeless people. One of the largest Housing First programs in Europe was established with the Danish homelessness strategy from 2009 to 2013 and a follow-up program from 2014 to 2016. Results from the Danish program showed similar positive outcomes of Housing First as documented in other countries. However, evaluation research also uncovered barriers to scaling up and mainstreaming Housing First into the general welfare system. This article analyses the coverage rate of Housing First in the overall population of homeless people in Denmark. Results show that in the municipalities that were part of the program only one in twenty homeless people were enrolled in the program. Moreover, following Kuhn and Culhane's (1998) typology of shelter users, the study examines the proportion amongst the transitional, episodic, and chronic shelter users that were enrolled in the Housing First program during the program period. Even in the primary target group for Housing First, the chronic shelter users, only $11 \%$ were included in the Housing First program.
\end{abstract}

\section{Keywords}

cluster analysis; Denmark; homelessness; Housing First; housing shortage; national homelessness strategy; shelter users

\section{Issue}

This article is part of the issue "Vulnerable and Disadvantaged Groups: On the Margins of the Welfare State?", edited by Inger Lise Skog Hansen and Tone Fløtten (Fafo Institute for Labour and Social Research, Norway).

(C) 2018 by the author; licensee Cogitatio (Lisbon, Portugal). This article is licensed under a Creative Commons Attribution 4.0 International License (CC BY).

\section{Introduction}

Homelessness is one of the most severe manifestations of social marginalisation in western society. Even in Scandinavian countries with some of the world's most extensive welfare systems, homelessness is a persistent problem (Benjaminsen, 2017; Dyb \& Lid, 2017; Socialstyrelsen, 2017). In Denmark, national homelessness counts have shown a steady increase in homelessness over the last decade of $33 \%$ from 2009 to 2017 . Current figures show that, at a given time, about $0.12 \%$ of the Danish population is in an acute homelessness situation either as rough sleepers, shelter users, sofa surfers or in other homelessness situations (Benjaminsen, 2017).

Homelessness arises out of complex interactions between societal, systemic, and individual factors. Individuals with personal vulnerabilities such as mental illness and substance abuse problems are more likely to be exposed to adverse structural factors such as the lack of affordable housing, poverty, and unemployment, and are at much higher risk of homelessness than the general population (Fitzpatrick, 2005; Neale, 1997). Deficiencies in welfare systems such as the lack of adequate support for people with social problems or ill-health may further increase the risk of homelessness for vulnerable people (Busch-Geertsema, Edgar, O'Sullivan, \& Pleace, 2010). Moreover, the impact and interaction of various risk factors on both the macro and micro level may vary across time and between societies, e.g., with the extent of poverty and the effectiveness of welfare systems (Shinn, 2007; Stephens \& Fitzpatrick, 2007; Toro, 2007). In particular, scholars have emphasised how neoliberal welfare reforms and austerity measures are contributing to increasing the risk of homelessness in several coun- 
tries due to cuts in welfare benefits, reduced housing subsidies, and weakened social support systems (Padgett, Henwood, \& Tsemberis, 2015).

Despite the persistence of homelessness and the weakening of welfare systems in many countries, progress has been achieved in the understanding of interventions aimed at bringing people out of homelessness. An understanding of the importance of an early stabilisation of the housing situation has marked a paradigm shift away from the Treatment First approach towards the Housing First approach. The Treatment First approach assumes that homeless people with complex support needs due to mental illness or substance abuse problems first need to be stabilised and show compliance to treatment or even abstinence before they are assessed (by professionals) to be housing ready. However, according to the Housing First approach, being in an acute homelessness situation severely disrupts the ability to follow treatment and achieve psychosocial recovery (Padgett et al., 2015; Pleace, 2011). In contrast, the Housing First approach emphasises that immediate access to permanent housing in combination with the provision of intensive, flexible support, increases the chances of rehousing, recovery, and community integration for homeless people with complex support needs (Tsemberis, 2010). Thus, the Housing First approach represents a change in the underlying values and principles of the intervention and is widely based on consumer-oriented clinical approaches such as psychiatric rehabilitation, harm reduction and trauma-informed care (Padgett et al., 2015). Moreover, a crucial element of Housing First is the provision of intensive, flexible social support tailor-made to individual needs through systematic, evidence-based methods such as Assertive Community Treatment (ACT) and Intensive Case Management (ICM) (Tsemberis, 2010).

The effectiveness of the Housing First approach has been documented in a growing number of randomised controlled trials and other studies showing that Housing First increases the chances of rehousing amongst homeless people with complex support needs. The first studies from the USA were attached to the original model developed by the Pathways Housing First organisation (Tsemberis, Gulcur, \& Nakae, 2004). Since then the Housing First model has been tested not only in the USA but also in many other countries. In Canada and France, large randomised trials have corroborated that Housing First is an effective approach to rehousing homeless people (Goering et al., 2014; Latimer et al., 2017; Rhenter et al., 2018; Stergiopoulos et al., 2015; Tinland et al., 2013). As the Housing First model gradually spread from North America to Europe, Housing First projects have been developed in various European countries such as Denmark, Finland, France, Netherlands, Norway, Portugal, Sweden, Spain and the UK. However, in Europe, besides the experimental project in France, only Denmark and Finland have had relatively large Housing First programs, whereas, in most European countries, Housing First has been introduced only in smaller pilot projects. A compar- ative European study on Housing First concluded that a high housing retention rate was found in Housing First projects in Denmark, Netherlands, Portugal, and Scotland. However, the study also pointed to differences in the implementation of the model compared to the original model in the USA (Busch-Geertsema, 2013, 2014). According to Busch-Geertsema (2014), differences in welfare and housing systems must be taken into consideration when implementing Housing First in Europe compared to the USA. In particular, in a number of European countries, including Denmark, housing for vulnerable people is often provided through public or social housing and the private rental sector plays a smaller role in rehousing homeless people in these countries.

Moreover, in Northern European countries, the profile of homelessness is different than in the USA. In countries with lower levels of poverty and more extensive welfare systems, such as the Nordic countries, a higher proportion of homeless people has complex support needs, as fewer people become homeless primarily due to poverty and housing affordability problems when compared to the USA (Benjaminsen \& Andrade, 2015; Shinn, 2007; Stephens \& Fitzpatrick, 2007; Stephens, Fitzpatrick, Elsinga, van Steen, \& Chzen, 2010; Toro, 2007). It is necessary to reflect on the implications of these differences in the profile of homeless people when importing an intervention model developed in a different economic and social context. However, as homelessness in Denmark and other Northern European countries is more concentrated in a group of people with complex support needs, we may assume that a higher share of homeless people in these countries belong to the target group for Housing First than in the USA, as Housing First with its combination of housing and intensive social support is aimed at homeless people with complex support needs, whereas homeless people with low support needs and who are mainly homeless due to poverty, are in need of housing but would not need the intensive social support provided through ACT or ICM.

Along with Finland, which pioneered Housing First in Europe in 2007, Denmark was amongst the first European countries to introduce the Housing First approach, as Housing First became the overall principle of a national homelessness strategy from 2009 to 2013. A key component of the Danish homelessness strategy was a Housing First program which remains among the largest in Europe as about one thousand people went through the first program from 2009 to 2013 (Rambøll \& SFI, 2013). The first program was succeeded by a follow-up program from 2014 to 2016 with nearly 400 participants (Benjaminsen et al., 2017).

Despite this relatively large program, homelessness in Denmark has generally increased throughout this period by 33\% from 2009 to 2017, measured through nationwide homelessness counts (Benjaminsen, 2017). At first glance, it may seem paradoxical that homelessness in Denmark has increased at the same time as a large homelessness program has been rolled out. A likely ex- 
planation is that although the homeless individuals who participated in the Danish Housing First program were widely rehoused, these positive outcomes could not offset more general structural changes in the Danish welfare system over the same period that contributed to an overall increase in homelessness. In Denmark, similar to other countries, welfare reforms have introduced reductions in social benefits for broader groups of welfare recipients and, at the same time, an increasing shortage of affordable housing has emerged in larger Danish cities and towns as a consequence of re-urbanisation and a strong increase in housing demand in urban centres. Such adverse structural factors are likely to have contributed to the general increase in homelessness over the period. At the same time, the lack of affordable housing posed barriers to scaling up and mainstreaming Housing First on local level (Benjaminsen et al., 2017; Rambøll \& SFI, 2013).

This article explores the challenges of scaling up Housing First by analysing the coverage rates of the Danish Housing First program in the potential target population of all homeless people in Denmark and in specific subgroups amongst the homeless. The analysis is based on combining individual data on homelessness from the national homelessness counts and from the homeless shelter system with data on the participants of the Housing First program and calculating the proportion among homeless people who were enrolled in the program. Moreover, the analysis draws on the typology of shelter users developed by Kuhn and Culhane (1998), who identified three distinct groups of shelter users: the transitional, the episodic, and the chronic shelter users. Based on a similar analysis on Danish shelter data, the article investigates what types of shelter users were predominantly included into the Danish Housing First program by analysing the proportions amongst the transitional, episodic, and chronic shelter users that received a Housing First intervention through the program. Thus, the article contributes to an under-researched area in the literature, namely the coverage rate of Housing First programs within the overall population affected by homeless and within particular subgroups among homeless people drawing on existing typologies.

Section two provides an overview of patterns and profiles of homelessness in Denmark and section three gives a more detailed account of the Danish homelessness strategy and the Housing First program. Section four describes data and methods, and section five presents the empirical results. Section six discusses the results and gives concluding remarks.

\section{Homelessness in Denmark}

Homelessness in Denmark is generally monitored through national homelessness counts that have been conducted every second year since 2007 . The count is a point-in-time count during one week and the definition of homelessness is widely based on the modified version
("ETHOS-light") of the European Typology of Homelessness and Housing Exclusion (Edgar, Harrison, Watson, \& Busch-Geertsema, 2007). The count includes not only rough sleepers and shelter users but also broader categories of homelessness situations such as people staying temporarily with friends or family ("sofa surfers") or in short-term transitional housing without a permanent contract.

The latest national homeless count in 2017 showed that 6,635 people were in a homelessness situation during the count week. About one in ten (648 individuals) were recorded as rough sleepers. The majority of homeless people were staying in homeless shelters $(2,217$ individuals) or temporarily with family or friends $(2,177$ individuals), and the rest were in other homelessness situations such as short-term transitional housing, staying in hotels due to homelessness, or awaiting discharge from hospitals or other treatment facilities without a housing solution (Benjaminsen, 2017).

The national homeless counts have documented a considerable increase in homelessness in Denmark during recent years. An adjustment of the definition was made following the first count in 2007 and figures from 2009 are therefore generally used as a base for comparisons over time. During the period from 2009 to 2017, homelessness increased by $33 \%$ from 4,998 homeless people recorded in week six, 2009 to 6,635 homeless people in week six, 2017. Whilst an increase in homelessness occurred in many different cities and towns, the increase was particularly high in the belt of suburban municipalities around Copenhagen and in Denmark's second largest city, Aarhus. As previously mentioned, the increasing shortage of affordable housing, especially in larger cities, is likely a main driver of the general increase in homelessness, as the lack of access to affordable housing increases the risk of homelessness amongst vulnerable individuals and marginalised youth (Benjaminsen, 2017).

The homelessness counts also provide information on the profile of homeless people and their support needs. About half of the homeless people recorded in the most recent count had a mental illness and about three out of five had substance abuse problems. In total, four out of five homeless people had a mental illness, substance abuse problems, or both. In general, pointin-time counts run the risk of overestimating the share amongst homeless people with complex support needs as point-in-time counts will capture a higher share of people in long-term homelessness and a lower share of short-term homeless people compared to longitudinal data. However, research on longitudinal shelter data has corroborated that a high proportion of homeless people in Denmark has complex support needs (Benjaminsen \& Andrade, 2015; Benjaminsen, 2016; Nielsen, Hjorthøj, Erlangsen, \& Nordentoft, 2011). These findings generally imply that a high share among homeless people will need relatively intensive support when being rehoused. 


\section{The Homelessness Strategy Program and Its Follow-Up Program}

Following the first national homelessness count in 2007 a homelessness strategy program was launched by the Danish Government with an initial program period from 2009 to 2012 and later extended to 2013. Due to the emerging evidence on the merits of the Housing First approach, it was decided that Housing First would be the overall principle of the strategy. Following the Housing First approach, key components of the Danish homelessness strategy were to provide access to permanent housing for homeless people in combination with offering individual, flexible, and intensive social support. An important part of the program was to test the evidence-based support methods that had been used in Housing First programs in the USA by developing similar interventions in a Danish setting.

Three different support methods were included in the Danish program: ACT, ICM, and Critical Time Intervention (CTI). The ACT-method is based on multidisciplinary floating support where a team of social support workers, a psychiatrist, an addiction treatment specialist, a nurse, a social office worker, and an employment consultant provide tailor-made support aimed at individuals with complex support needs. Through this integrated and holistic approach, ACT is particularly suitable for people with a dual-diagnosis of mental illness and substance abuse problems (Tsemberis, 2010). The ICM-method is a case management-based form of support where a social support worker gives social and practical support in everyday life and assists in bridge-building to existing welfare services by coordinating the use of other treatment and support services for the individual. ICM-support is aimed at individuals with considerable support needs due to mental illness or substance abuse problems (Stergiopoulos et al., 2015; Tsemberis, 2010).

Besides ACT and ICM, CTI was also included in the Danish program. The CTI-method offers support for a limited time period of nine months in the critical transition period when the individual moves from a homeless shelter into own housing. The intervention is highly systematic and structured into three three-month-long phases. During this period the CTI-worker not only gives social and practical support, but also supports the individual in building a support network and connecting to mainstream services in the local community (Herman et al., 2011; Susser et al., 1997). As a time-limited form of support, the CTI-method diverges from a key principle of Housing First, which is providing support for as long as the individual requires. However, a rationale for bringing CTI into the Danish program next to ICM and ACT was to further differentiate the provision of support according to support needs, as CTI was intended to be given to homeless people with less intensive support needs than those in need of ACT- or ICM-support.

Out of 98 Danish municipalities, 17 were included in the strategy program from 2009 to 2013. Although not all Danish municipalities were part of the program, the 17 municipalities included many larger cities and towns and represented $71 \%$ of total homelessness in Denmark according to the homelessness count in 2009. Housing for the program was widely provided through access to public housing. Public housing comprises about $21 \%$ of the total Danish housing stock and is open to everybody through general waiting lists regardless of income level. Besides the general waiting lists, municipalities have a right to refer up to one-quarter of all vacancies in public housing to priority groups in acute housing need such as families with children, people with handicaps, people with psychosocial vulnerabilities, and homeless people. However, before the onset of the program, referral to public housing through this targeted allocation system was often conditioned upon housing readiness and requirements of treatment or even abstinence. An important element in the shift towards Housing First was to facilitate a change in local practices, including housing allocation systems, to let homeless people gain access to housing without demonstrating prior housing readiness.

\subsection{Results from the Strategy Program and Its Follow-Up Program}

The strategy program was followed by evaluation research which monitored the outcomes of the interventions for the participants (Rambøll \& SFI, 2013). In total, about one thousand individuals received housing and support through the Housing First program from 2009 to 2013. The ICM-program was the largest subprogram with about 700 people receiving ICM-support, whereas about 300 individuals received CTI-support. Although about a third of homeless people in Denmark have a dual diagnosis, the ACT-subprogram was the smallest string of the Danish program as only one ACT-team was established in the city of Copenhagen and about 90 individuals received support from the ACT-team (Rambøll \& SFI, 2013).

Outcome measurement was performed on the intervention group and did not include any control groups. The outcome monitoring showed that Housing First had successful outcomes for the majority of those participating in the program as about nine of out ten people who were rehoused and received floating support through the program were able to retain their housing throughout the observation period (Benjaminsen, 2013; Rambøll \& SFI, 2013). However, the Danish program was not subjected to the same rigorous measurement as in the randomised controlled trials in the USA, Canada, and France. Instead, the measurement was based on outcome measurement in the intervention group with no application of control groups. A reason for measuring outcomes only in the intervention groups was that the program was rolled out relatively broadly in many municipalities from the beginning and there was concern that a more rigorous measurement design would complicate the implementation of the program and might reduce the willingness of municipalities to take part in the program. 
Following the positive results of the strategy program, a follow-up program-The Implementation Project-was initiated from 2014 to 2016 which aimed at anchoring Housing First in the municipalities from the first program and extending the program into new municipalities. Whilst three of the 17 municipalities from the initial program were not part of the follow-up program, 24 municipalities took part in the follow-up program. While the follow-up program generally showed very similar outcomes on an individual level with high housing retention rates (Benjaminsen et al., 2017), it was also evident that the overall level of homelessness in Denmark had increased during the period as 4,998 homeless people were recorded in the homelessness count in 2009, rising to 5,820 homeless people in 2013 after the end of the first strategy period, and to 6,635 homeless people in 2017 after the end of the follow-up program (Benjaminsen, 2017). In the concluding section, this development will be discussed in light of the empirical analysis in section 5 on the coverage rates of the Housing First program within the homeless population in Denmark.

\section{Data and Methods}

While the previous sections have presented the context of homelessness in Denmark, the Danish homelessness strategy and the Housing First program, the remaining part of the article investigates the coverage rates of Housing First in the potential target population of all homeless people in Denmark and among homeless people with complex support needs.

Data for the study is based on administrative data on shelter users obtained from Statistics Denmark, data from the national homelessness counts and data on participants in the Housing First program under the Danish Homelessness Strategy and the follow-up program. Data on shelter users covers the period from 2009 to 2015 and was collected during this period by The Social Appeals Board from all homelessness shelters in Denmark operating under $\S 110$ in the Law on Social Service (Ankestyrelsen, 2016). The data on shelter users contain information on the episodes and length of shelter stays. Data from homeless shelters has been combined with individual data from four national homelessness counts during the same period on people in other types of homeless situations such as rough sleepers and sofa surfers that were in contact with the general welfare system and recorded in the homelessness counts. The combination of data from both the shelter system and the homelessness counts gives the most comprehensive measure of the overall number of people affected by homelessness in Denmark during the seven-year measurement period. To control for double counting, unique identifiers were used across data sets. The analysis excludes a small proportion of individuals that were recorded in the homelessness count without unique identifiers. Data on participants of the Housing First program was collected as part of the evaluation of the program and was made available for the study by The National Board of Social Services. The data gives information on the type of social support received. Individual data from the shelter system, the homelessness counts, and on the participants of the Housing First program was linked by Statistics Denmark through unique identifiers that were anonymous to the researcher. Permission for the study was granted by the Danish Data Protection Agency.

The statistical analysis calculates the share of homeless people (shelter users and people in other homelessness situations) that were enrolled in the Housing First program during the homelessness strategy period from 2009 to 2013, and during the entire period from 2009 to 2015. Following Kuhn \& Culhane (1998) a cluster analysis is applied to construct a typology of subgroups amongst the homeless. This analysis is restricted to homeless shelter users as continuous data recorded all year around is needed for this analysis. The measurement of distances between cases is based on the differences in how many days and episodes that have been registered at a homeless shelter. Both the episode and days variables are standardised to have a mean equal to zero and a variance equal to one. Finally, the share of shelter users that were enrolled in the Housing First program within each cluster is calculated.

\section{Results}

To examine the coverage rate of the Danish Housing First program within the potential target population of homeless people, Table 1 shows the proportion that participated in the Housing First program amongst all homeless people in Denmark and amongst homeless people in the municipalities that participated in the program. As previously mentioned, there were 17 municipalities participating in the homelessness strategy program, whereas 27 municipalities participated either in the strategy program, the follow-up program, or both. Due to an overlap of individuals who were recorded as homeless in both the homelessness strategy period and in the period of the follow-up program, the figures in the two left-hand columns cover the strategy period (2009-2013) and the two right-hand columns give the figures for the homelessness strategy and the follow-up program combined for the entire period from 2009 to 2015 . When data were drawn for the analysis, shelter data were only available until 2015 and thus 2016 is not covered by the table. Furthermore, the analysis is restricted to individuals who were 18 years or older in 2009 . For each period, the proportion of homeless people that participated in the Housing First program is shown in total (one of the three interventions) and for each of the three subprograms (CTI, ICM or ACT).

In total there were 21,519 individuals recorded as homeless in Denmark from 2009 to 2013 in either data from homeless shelters or in the national homelessness counts and 14,055 of these individuals were recorded in 
Table 1. Proportion of homeless people in Denmark receiving CTI-, ICM- or ACT-support from the Housing First program under the homelessness strategy or the follow-up program. Source: Benjaminsen and Enemark (2017, p. 110).

\begin{tabular}{cllll}
\hline & \multicolumn{2}{l}{$\begin{array}{l}\text { Homelessness strategy } \\
\text { Analysis period 2009-2013 }\end{array}$} & \multicolumn{2}{l}{$\begin{array}{l}\text { Homelessness strategy and follow-up program } \\
\text { Analysis period 2009-2015 }\end{array}$} \\
\hline Intervention & $\begin{array}{l}\text { Homeless people } \\
\text { recorded in all } \\
\text { of Denmark }\end{array}$ & $\begin{array}{l}\text { Homeless people } \\
\text { recorded in 17 } \\
\text { program municipalities }\end{array}$ & $\begin{array}{l}\text { Homeless people } \\
\text { recorded in all } \\
\text { of Denmark }\end{array}$ & $\begin{array}{l}\text { Homeless people } \\
\text { recorded in 27 } \\
\text { program municipalities }\end{array}$ \\
\hline None of the three & 96 & 94 & 96 & 95 \\
One of the three & 4 & 6 & 4 & 5 \\
CTI & 1 & 2 & 1 & 2 \\
ICM & 3 & 4 & 2 & 3 \\
ACT & $<1$ & $<1$ & $<1$ & $<1$ \\
Total & 100 & 100 & 100 & 100 \\
\hline $\mathrm{N}$ & 21,519 & 14,055 & 27,214 & 20,876 \\
\hline
\end{tabular}

Note: Percentage values.

the 17 municipalities that were part of the strategy program. Out of the homeless people recorded nationwide in the first period only $4 \%$ participated in the Housing First program. When the analysis is restricted to homeless people in the 17 municipalities that took part in the program, $6 \%$ of homeless people in these municipalities participated in the Housing First program. Throughout the entire period from 2009 to 2015, there were 27,214 individuals recorded as homeless nationwide and 20,876 of these individuals were recorded in the 27 municipalities that were part of the programs. Out of all homeless people in Denmark recorded throughout the entire period from 2009 to $2015,4 \%$ participated in one of the two programs and $5 \%$ when the analysis is restricted to the 27 municipalities participating in the programs.

The results generally show that relatively few homeless people participated in the Housing First program, even in the municipalities that were part of the program. However, it should be considered that homeless people may have received interventions from various other services than the Housing First program. Municipalities may refer homeless people to housing without being attached to these programs. Moreover, homeless people may have received other forms of support from either psychiatric services or from other municipal floating support teams, as municipalities in Denmark operate general floating support teams that provide support for broader groups of vulnerable people, such as people with mental illness or substance abuse problems. Yet, other forms of floating support would seldom be as intensive and flexible as the high-intensive forms of support that were provided through the Housing First program.

To examine what type of homeless people participated in the Housing First program, the profile was analysed following Kuhn and Culhane's (1998) typology of homelessness that distinguishes between transitional, episodic and chronic homelessness. Based on shelter data from New York City and Philadelphia, Kuhn and Culhane (1998) identified three different subgroups amongst shelter users. The transitional shelter users were characterised by relatively few and short experiences of shelter use, and they seldom returned to the shelter system. In contrast, the episodic shelter users had frequent and repeated shelter stays of relatively short length whereas the third group, the chronic shelter users, had few but very long stays. According to Kuhn and Culhane (1998), the transitional shelter users had less complex support needs than the two other groups as fewer among the transitional shelter users had either mental illness or substance abuse problems compared to a high share with mental illness or substance abuse problems amongst both the episodic and chronic shelter users.

Previous research on Danish shelter data covering a time period from 1999 to 2009 showed that the same three groups, the transitional, episodic, and chronic shelter users could be found among Danish shelter users (Benjaminsen \& Andrade, 2015). However, a difference compared to the USA was that in Denmark a high share of the transitional shelter users has a mental illness or substance abuse problems, whereas fewer among the transitional shelter users in the USA have complex support needs. This difference reflects that in Denmark, with an extensive welfare system and a lower level of poverty, even short-term homelessness is more concentrated to people with complex support needs compared to the USA where homelessness, to a higher extent, affects wider groups of poor people without complex support needs. Yet, despite a relatively high proportion with mental illness or substance abuse problems amongst the transitionally homeless in Denmark, we may assume that people staying in homelessness shelters only once and for a short period, on average, have less complex support needs compared to long-term shelter users. Thus, a distinction between the transitional, episodic, and chronic shelter users provides a good starting point for assessing to what extent different subgroups of homeless people were targeted by the Danish Housing First program.

As continuous data recorded throughout the year is needed for this analysis, the analysis was restricted to 
homeless shelter users and did not include the individuals in other homelessness situations that were measured through the homelessness counts and who were included in Table 1. An analysis of the types of shelter users was applied to a population of individuals that used Danish homeless shelters from 2009 to 2015, the period covered by the strategy program and the follow-up program, and participation rates in the Housing First program were calculated for each group (Table 2). The cluster analysis was based on the number of shelter stays and the length of shelter stays similar to the cluster analysis performed by Kuhn and Culhane (1998). The classification was based on the cluster analysis grouping shelter users into clusters with a similar pattern on two indicators: the number of shelter stays and the length of shelter stays. Then, the percentage of shelter users in each group that had participated in the Housing First program and each of the three subprograms (CTI, ICM or $\mathrm{ACT}$ ) was examined. The general cluster analysis dividing shelter users into the three groups was performed for all municipalities including both program and non-program municipalities. Due to the methodological issue of leftand right-censoring, the analysis was restricted to shelter users who were not enrolled in a shelter at the onset of the measurement period in $\mathbf{2 0 0 9}$ or at the end of the period in 2015, as the full length of the shelter stay is not known in either case. Thus, the cluster analysis was based on 15,107 individuals out of a total of 21,555 individuals who used shelters during the period.

Of the shelter users in the 27 municipalities that were part of the program, $26 \%$ were classified as chronic (longterm) shelter users, $11 \%$ as episodic shelter users, and
$63 \%$ as transitional (short-term) shelter users. Thus, there was a slightly higher share of chronic shelter users in the program municipalities compared to an average of $23 \%$ for all municipalities. Participation rates in the program were calculated for each type of shelter users for the 27 municipalities in the program. The analysis shows that the highest participation rate in the Housing First program is found among the chronical shelter users, as $11 \%$ in this group were part of the program and received either CTI-, ICM- or ACT-support as part of a Housing First intervention. A similar level is found amongst the episodic shelter users, as $10 \%$ in this group were part of the program. The lowest participation rate in the Housing First program is found amongst the transitional shelter users, where only $4 \%$ were enrolled in the program throughout the period. This finding shows that Housing First, to a wide extent, has targeted the groups with high support needs - the chronic and episodic shelter users-rather than the group of transitional shelter users, who are likely to have the lowest level of support needs. Although the program as a whole reached only a modest share of all shelter users, the results show no apparent indications of cream-skimming as the Housing First interventions appear to have primarily targeted the shelter users they were supposed to, namely long-term shelter users.

\section{Conclusion}

While the evaluation research on the Danish homelessness strategy and its follow-up program showed that Housing First was successful for most of the homeless people who participated in the program, the analysis in

Table 2. Proportion of transitional, episodic, and chronic shelter users receiving CTI-, ICM- or ACT-support from the Housing First program under the homelessness strategy program or the follow-up program. Source: Benjaminsen and Enemark (2017, pp. 75, 111).

\begin{tabular}{|c|c|c|c|c|}
\hline \multirow[b]{2}{*}{ Intervention } & \multicolumn{4}{|c|}{ Type of shelter user } \\
\hline & Transitional & Episodic & Chronic & All shelter users \\
\hline None of the three methods & 96 & 90 & 89 & 93 \\
\hline One of the three methods & 4 & 10 & 11 & 7 \\
\hline CTI & 1 & 3 & 5 & 2 \\
\hline ICM & 2 & 6 & 6 & 4 \\
\hline ACT & $<1$ & $<1$ & $<1$ & $<1$ \\
\hline Total & 100 & 100 & 100 & 100 \\
\hline $\mathrm{N}$ & 7,623 & 1,362 & 3,211 & 12,196 \\
\hline $\begin{array}{l}\text { Percentage of shelter users in each cluster } \\
\text { (program municipalities) }\end{array}$ & 63 & 11 & 26 & 100 \\
\hline
\end{tabular}

General cluster information

(all municipalities)

$\mathrm{N}$

Percentage in each cluster

No. of shelter stays

Length of each shelter stay (days)

Total length of shelter stays (days)

Note: Percentage values.

\begin{tabular}{rrrr}
10,130 & 1,542 & 3,435 & 15,107 \\
67 & 10 & 23 & 100.0 \\
1.6 & 13.3 & 2.5 & 3.0 \\
38.3 & 26.2 & 241.2 & 71.1 \\
61.7 & 349.3 & 602.0 & 213.9 \\
\hline
\end{tabular}


this article shows that the program included only a relatively small portion of people who were recorded as homeless in Denmark during the program period. In the municipalities that were part of the program, only about one in twenty homeless people received a Housing First intervention through either the homeless strategy or its follow-up program from 2009 to 2015.

As not all homeless people are necessarily in need of the relatively intensive Housing First intervention, the study also investigated what groups of homeless people were predominately targeted by the Housing First program. This analysis made use of the typology of homelessness developed by Kuhn and Culhane (1998) distinguishing between transitional, episodic, and chronic homelessness. This analysis was carried out only among individuals who had used a homeless shelter during the measurement period due to the need for continuous data on the frequency and length of shelter stays in order to perform the cluster analysis. The highest proportion who participated in the Danish Housing First program was found among the chronical (long-term) shelters users whereas the lowest proportion was found among the transitional shelter users. Thus, the findings show that the Housing First program widely targeted those homeless people it was intended for. Yet, even amongst the chronically homeless in the 27 municipalities that participated in the program, only $11 \%$ were included in the Housing First program and received either ACT-, ICM- or CTI-support.

The findings show that even in Denmark where Housing First has been embedded in a national homelessness strategy with Housing First as its overall principle, these interventions only cover a minor part of their primary target group. The evaluation research attached to the programs examined barriers to implementing the interventions on a local level. A major challenge highlighted by the evaluation research were barriers for providing affordable housing for the program, as an increasing shortage of affordable housing was reported not only in larger cities, but also in many medium-sized towns (Benjaminsen et al., 2017). Even though allocation mechanisms to public housing were widely used to provide access to public housing, the supply of vacancies was often too scarce, and even in public housing rent levels were often too high for people on social assistance benefits. In the Danish program, a deviation from the original Pathways Housing First model was that the rent needed to be paid through ordinary social benefits, which do not have a separate component for housing costs. Although social benefits in Denmark are relatively generous compared to many other countries, not all public housing units have a low enough rent to be paid through social assistance benefits. Moreover, cuts in welfare benefits-in particular for young people-have been introduced in recent years as part of general welfare reforms, further widening the gap between income and rent levels.

Another important barrier identified in the evaluation research concerns the capacity in municipalities to provide floating support through the systematic and intensive support methods (ACT, ICM, and CTI). This challenge is illustrated most clearly in the case of the ACTsubprogram. Despite homelessness in Denmark being widely concentrated to people with complex support needs, only one ACT-team was established as part of the program. However, given the general profile of homeless people in Denmark, where one-third of homeless people have a dual diagnosis, there is a strong potential for extending ACT-support to a much larger proportion of homeless people and to long-term shelter users, in particular. These barriers to the general capacity of providing intensive support must also be seen in relation to the resources available for the programs. During the first program period from 2009 to 2013, funding was mainly provided by the central government, but in the follow-up program, municipalities widely needed to fund support services out of their general local budgets. Although funding for the interventions in the followup program was widely provided by the municipalities, it may be difficult for municipalities to find funding for further upscaling the intensive support services, as municipal budgets are generally constrained by an overall spending cap from the central government with strong competition for resources across different domains of local welfare services.

Moreover, the evaluation research also pointed to the general challenge of implementing a mind-shift from Treatment First to Housing First. This involves changing processes on many levels as organisational structures and practices need to be adapted. These processes also involve many different local actors such as municipal social offices, homeless shelters, housing allocation offices etc. In some municipalities, these changes were more successful than in others.

The results of the study show that while new and innovative interventions enhance the chances of successful rehousing for homeless people, the development of such new approaches is only a first step. The process of scaling up these interventions to broader parts of potential target groups presents a greater challenge. While the Housing First program in the Danish homelessness strategy has been one of the largest Housing First programs in Europe, comparable in size to programs in Finland and France, even this relatively ambitious program anchored in a national homelessness strategy only achieved to provide about one in ten long-term homeless shelter users with a Housing First intervention. Policy implications of the study are that more focus should be given to extending and anchoring new and promising interventions such as Housing First into mainstream welfare services so that they do not remain innovative projects for the few. This also implies a need to overcome the detachment between homelessness policies and general housing and welfare policies as these deficiencies generally undermine the possibilities of providing housing and support interventions for all the homeless people who need them. 


\section{Acknowledgements}

The study draws on the results of a Danish study (see Benjaminsen \& Enemark, 2017) that was funded by The Ministry for Children and Social Affairs.

\section{Conflict of Interests}

The author declares no conflict of interests.

\section{References}

Ankestyrelsen (2016). Brugere af botilbud efter servicelovens $\S 110$. Årsstatistik 2015 [Users of $\S 110$ accommodation under the social assistance law. Annual statistics 2015]. Copenhagen: The Social Appeals Board.

Benjaminsen, L. (2013). Policy review up-date: Results from the Housing First based Danish homelessness strategy. European Journal of Homelessness, 7(2), 109-131.

Benjaminsen, L. (2016). Homelessness in a Scandinavian welfare state: The risk of shelter use in the Danish adult population. Urban Studies, 53(10), 2041-2063.

Benjaminsen, L. (2017). Hjemløshed i Danmark. National kortlægning 2017 [Homelessness in Denmark. National survey 2017]. Copenhagen: VIVE.

Benjaminsen, L., \& Andrade, S. B. (2015). Testing a typology of homelessness across welfare regimes: An analysis of shelter use in Denmark compared to the US. Housing Studies, 30(6), 858-876.

Benjaminsen, L., Dyrby, T. M., Enemark, M. H., Thomsen, M. T., Dalum, H. S., \& Vinther, U. L. (2017). Housing First i Danmark. Evaluering af implementerings- og forankringsprojektet i 24 kommuner [Housing First in Denmark. Evaluation of the implementation and anchoring project in 24 municipalities]. Copenhagen: SFI, Det Nationale Forskningscenter for Velfærd \& Rambøll.

Benjaminsen, L., \& Enemark, M. H. (2017). Veje ind og ud af hjemløshed. En undersøgelse af hjemløshedens forløb og dynamik [Pathways in and out of homelessness. A study of the sequences and dynamics of homelessness]. Copenhagen: VIVE.

Busch-Geertsema, V. (2013). Housing First Europe. Final report. Bremen: Giss.

Busch-Geertsema, V. (2014). Housing First Europe: Results of a European social experimentation project. European Journal of Homelessness, 8(1), 13-28.

Busch-Geertsema, V., Edgar, W., O’Sullivan, E., \& Pleace, N. (2010). Homelessness and homeless policies in Europe: Lessons from research, European Consensus Conference on Homelessness. Brussels: FEANTSA.

Dyb, E., \& Lid, S. (2017). Bostedsløse i Norge 2016. En kartlegging [Homelessness in Norway 2016. Mapping]. Oslo: NIBR.

Edgar, W., Harrison, M., Watson, P., \& Busch-Geertsema, V. (2007). Measurement of homelessness at
European Union level. Brussels: European Commission, DG Employment, Social Affairs \& Equal Opportunities.

Fitzpatrick, S. (2005). Explaining homelessness: A critical realist perspective. Housing, Theory and Society, 22(1), 1-17.

Goering, P., Veldhuizen, S., Watson, A., Adair, C., Kopp, B., Latimer, E., . . . Aubry, T. (2014). National at home/chez soi final report. Calgary: Mental Health Commission of Canada.

Herman, D., Conover, S., Gorroochurn, P., Hinterland, K., Hoepner, L. ,\& Susser, E. (2011). Randomized trial of critical time intervention to prevent homelessness after hospital discharge. Psychiatric Services, 62(7), 713-719.

Kuhn, R., \& Culhane, D. (1998). Applying cluster analysis to test a typology of homelessness by pattern of shelter utilization: Results from the analysis of administrative data. American Journal of Community Psychology, 26(2), 207-232.

Latimer, E. A., Rabouin, D., Cao, Z., Ly, A., Powell, G., Aubry, T., . . Goering, P. N. (2017). Costs of services for homeless people with mental illness in 5 Canadian cities: A large prospective follow-up study. CMAJ Open, 5(3), E576-E585.

Neale, J. (1997). Homelessness and theory reconsidered. Housing Studies, 12(1), 47-61.

Nielsen, S. F., Hjorth $\varnothing$, C. R., Erlangsen, A., \& Nordentoft, M. (2011). Psychiatric disorders and mortality among people in homeless shelters in Denmark: A nationwide register-based cohort study. Lancet, 377(9784), 2205-2214.

Padgett, D., Henwood, B., \& Tsemberis, S. (2015). Housing First. Ending homelessness, transforming systems, and changing lives. New York, NY: Oxford University Press.

Pleace, N. (2011). The ambiguities, limits and risks of Housing First from a European perspective. European Journal of Homelessness, 5(2), 113-127.

Rambøll, \& SFI. (2013). Hjemløsestrategien. Afsluttende rapport [The homelessness strategy: Final report]. Copenhagen: Rambøll \& SFI.

Rhenter, P., Moreau, D., Laval, C., Mantovani, J., Albisson, A., Suderie, G., . . . Girard, V. (2018). Bread and shoulders: Reversing the downward spiral, a qualitative analysis of the effects of a Housing First-type program in France. International Journal of Environmental Research and Public Health, 15(3), 520.

Shinn, M. (2007). International homelessness: Policy, socio-cultural, and individual perspectives. Journal of Social Issues, 63(3), 657-677.

Socialstyrelsen. (2017). Hemlöshet 2017: Omfattning och karaktär [Homelessness 2017: Extent and profile]. Stockholm: Socialstyrelsen.

Stephens, M., \& Fitzpatrick, S. (2007). Welfare regimes, housing systems and homelessness. How are they linked? European Journal of Homelessness, 1, 201-212. 
Stephens, M., Fitzpatrick, S., Elsinga, M., van Steen, G., \& Chzen, Y. (2010). Study on housing exclusion: Welfare policies, housing provision and labour markets. Brussels: European Commission, Directorate-General for Employment, Social Affairs \& Equal Opportunities.

Stergiopoulos, V., Gozdzik, A., Misir, V., Skosireva, A., Connelly, J., Sarang, A., . . McKenzie, K. (2015). Effectiveness of Housing First with Intensive Case Management in an ethnically diverse sample of homeless adults with mental illness: A randomized controlled trial. PlosOne, 10(7), e0130281. https://doi.org/ 10.1371/journal.pone.0130281

Susser, E., Valencia, E., Conover, S., Felix, A., Tsai, W., \& Wyatt, R. J. (1997). Preventing recurrent homelessness among mentally ill men: A 'critical time' intervention after discharge from a shelter. American Jour- nal of Public Health, 87(2), 256-262.

Tinland, A., Fortanier, C., Girard, V., Laval, C., Videau, B., Rhenter, P., . . A Aquier, P. (2013). Evaluation of the Housing First program in patients with severe mental disorders in France: Study protocol for a randomized controlled trial. Trials, 14, 309.

Toro, P. A. (2007). Toward an international understanding of homelessness. Journal of Social Issues, 63(3), 461-481.

Tsemberis, S., Gulcur, L., \& Nakae, M. (2004). Housing First, consumer choice and harm reduction for homeless individuals with a dual diagnosis. American Journal of Public Health, 94(4), 651-656.

Tsemberis, S. (2010). Housing First: The pathways model to end homelessness for people with mental illness and addiction. Minneapolis, MN: Hazelden Press.

\section{About the Author}

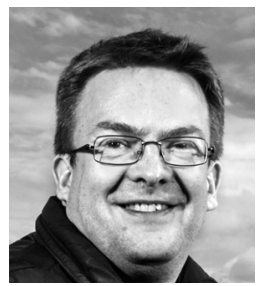

Lars Benjaminsen is a Senior Researcher at VIVE: The Danish Center for Social Science Research. He is also a member of the European Observatory on Homelessness under FEANTSA (European Federation of National Organisations working with the Homeless). He has conducted several studies on social marginalisation and homelessness in Denmark and on social interventions for socially vulnerable groups. He is responsible for the nationwide homelessness counts in Denmark and has conducted studies on Housing First interventions for homeless people in Denmark. 